\title{
Assessing Energy Improvement Potential from Efficiency and Renewable Interventions at Neighborhood Level
}

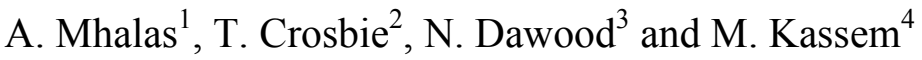 \\ 1,2,3,4 Technology Futures Institute, Teesside University, TS1 3BA, UK; \\ Email: \{a.mhalas, t.crosbie, n.n.dawood, m.kassem\}@tees.ac.uk
}

\begin{abstract}
Tools for the estimation of energy performance improvement, achievable through energy efficiency and renewable energy interventions, with decision making capabilities for policy implementation at neighborhood level are still lacking. In this paper, we present a proof-of-concept tool that integrates a decision support mechanism for enabling opinions and criteria of various decision makers to be taken into account during the implementation of energy efficiency interventions at neighborhood level. The tool is based on integrating information from aerial and terrestrial imagery, digital maps and national databases and statistics providing housing data on a GIS platform. The testing of the tool with the involvement of local authorities and social housing providers demonstrated that the tool can support policy makers in making informed decisions with regard to the implementation of energy policies and initiatives and contribute to meeting $\mathrm{CO}_{2}$ emission reduction targets.
\end{abstract}

\section{INTRODUCTION}

Several energy modeling tools have been developed over a number of years to estimate the current and future energy consumption. Some of the notable models include Building Research Establishment's Housing Model for Energy Studies (Shorrock et al. 1997); Johnston Energy and CO2 Emission Model (Johnston 2003); UK Domestic Carbon Model (Boardman et al. 2005); Energy and Environmental Prediction (EEP) Tool (Jones et al. 2007) and Community Domestic Energy Model (Firth et al. 2010). All these models have the same energy calculation engine which is the BREDEM (Building Research Establishment Domestic Energy Model). The transparency of models in terms of data sources and model structures is recognized as a crucial issue in deployment of the models. However for most of these models, no access is available to the raw input data and core calculation algorithms including the modified BREDEM-type modules. These models assist in informing policy development but none of them assist in implementing these policies. In addition, all models above 
except for EEP rely on standard archetype models of dwellings which are limited in number. EEP tried to overcome this challenge through drive-through survey of dwellings to gather information, however, survey of 55,000 dwellings in Neath Port Talbot District Borough Council required 18 person months, which is hugely time consuming (Jones et al. 2007).

This research intends to address these gaps through developing a proof-of-concept tool that integrates energy databases with visualization systems and multi-criteria analyses. For this purpose, the Standard Assessment Procedure (SAP) was selected as a main element of the proof-of-concept tool. SAP is underpinned by BREDEM and is the recommended tool by the Department of Energy and Climate Change (DECC) for assessing and comparing the energy and environmental performance of dwellings. SAP is now the UK's National Calculation Methodology, meeting one of the requirements of the Energy Performance of Buildings Directive (DECC/BRE 2010). The tool permits stakeholders to develop tailor-made scenarios of energy efficiency and renewable energy interventions and incorporates the use of multi-criteria decision analysis technique to assists stakeholders in meeting the requirements of the local development framework through incorporation environmental, technical, economic and social parameters as selection criteria.

\section{PROTOTYPE DEVELOPMENT}

The prototype tool is built on a GIS platform as it helps in integrating and managing vast and various formats of data and can connect various data sets together by common locational data e.g. address. The database created can be shared for various purposes including modeling and simulating scenarios. For this research, ArcGIS 10 was used as it is one of the most commonly used GIS platforms and supports the data from the identified sources. ArcGIS 10 provides a geo-processing functionality which allows personalizing tasks through inherent programming capabilities (Environmental Systems Research Institute 2010).

Each dwelling is considered an object consisting of attributes holding parameter related information. These attributes are derived from imagery, maps and databases which then act as input for energy balance equations. The energy balance equations estimate the baseline energy performance. Based on the existing characteristics of the stock, the potential for improvement to building fabric is identified and installation of renewable energy resources is quantified. Finally, an analytical hierarchy based decision support tool assists in selecting the most appropriate interventions based on 
environmental, technical, economic and social criteria.

\section{Baseline Energy Consumption}

The attributes of the dwelling objects are created form the input to the energy balance equations based on SAP and underpinned by BREDEM (DECC/BRE 2010). Using the programming functionalities in ArcGIS and MS-Excel, empirical and analytical equations for heat balance are modeled. The attributes from the object database and the equations of the energy sub-models, identified from SAP/BREDEM (DECC/BRE 2010) and used to evaluate the energy performance of the dwelling, include: heat losses due to ventilation, heat losses from building fabric such as doors, windows, roof, floor and walls, energy demand for water heating, internal gains from occupant metabolism, lighting and electrical appliances, cooking, water heating and boiler pumps for space and water heating and losses from evaporation; and external gains due to solar radiation through windows, space heating demand depending on the building geometry, heat losses, difference between internal temperature demand and external temperature and fraction of living space to total dwelling area, energy required by the heating system to meet the total (water and space) heat demand, electricity required for pumps, lighting and electrical appliances, energy cost depending on amount of electricity required from the grid and type and amount of fuel required for space and water heating, SAP rating based on the total cost of energy use (for space heating and lighting) normalized to the floor area of the dwelling, and $\mathrm{CO}_{2}$ emissions based on amount of electricity and total amount of fuel for space heating and water and their emission factors. The parameters affecting each attribute and the relationship among attributes are explained in Mhalas et al. (2013).

\section{Quantification of Energy Consumption and Carbon Emission Reduction Potential}

Studies by (Peacock et al. 2007; Jenkins 2010; Boardman 2007) and the discussions with the stakeholders undertaken as a part of this research has revealed the following as the most widely applicable energy performance improvement measures: changes to building fabric such as insulation of roof, walls, floor and installation of low-e double glazed windows; replacing the low efficiency boilers with 'A' rated condensing boilers; installation of solar photovoltaic panels for electricity generation and solar thermal for hot water generation; installation of micro wind-turbines for electricity generation; Installation of micro-combined heat and power ( $\mu$-CHP) unit to meet space heating demand and generate electricity as a by-product of heat generation, and installation of air source heat pumps (ASHP) and ground source heat pumps (GSHP) to meet space heating demand. The models involved in calculation of the impact of these 
interventions, the associated attributes and the output from the models are discussed in Mhalas et al. (2013).

\section{Decision Support System}

Energy planning decisions are complex as several parameters are involved in the process thus necessitating a decision support system. Furthermore, as the case with most energy-related decisions, various groups of decision makers are involved. Multi-criteria decision analysis (MCDA) deals with making decisions in presence of multiple stakeholders, criteria and alternatives (Wang et al. 2009). Pohekar et.al. (2004) have discussed several MCDA techniques and argue that Analytical Hierarchy Process (AHP) developed by (Saaty 1980) is one such technique most applicable for making sustainable energy planning decisions which is incorporated in this research. Based on the discussions with stakeholders during this study, the following were identified as important criteria based on which the selection of abovementioned interventions depends on: annual reduction in $\mathrm{CO}_{2}$ levels; initial investment (capital cost and grants received though government policies); return on investment (annual running cost to user and savings made through feed-in-tariff and renewable heat incentive); social acceptability (personal likeliness towards intervention), and ease of implementation (access to resources and timeline). Pairwise comparison is undertaken for each of the alternatives for each criterion. A scale of 1-9 is used to assess the intensity with 1 indicating equal importance and 9 extremely high importance (Saaty 1980). Based on the intensities assigned, a matrix is created. The matrix is then normalized and iterations are undertaken to identify the resultant eigen-vectors. The eigen-vectors established are the rankings that determine the preference for the alternatives based on the criteria. The input parameters and the output from the models involved along with the final output of the decision support system are explained in Mhalas et al. (2013).

\section{VALIDATION AND CASE STUDY}

To validate the framework, baseline energy calculations were undertaken on the developed proof-of-concept prototype, on a set of dwellings owned by a social housing provider in Middlesborough, UK. Thus the energy performance of the dwellings estimated by the method in this research is compared with the energy performance from actual survey of the property. 34 properties of various age and detachment were selected to ensure adequate representation of different archetypes. The results from the analyses indicate that the estimated energy performance is within a maximum range of $\pm 8 \%$ of the actual energy performance provided by the social 
housing provider. The average error over the 34 properties is just about $1 \%$ and the standard deviation of the error is 0.03 . The results are clearly within a close proximity of the actual energy performance and hence the approach is reliable.

Subsequent to the validation, a case study was undertaken for 756 dwellings in a Lower Level Super Output Area (LLSOA) in Middlesbrough as presented in Figure 1.

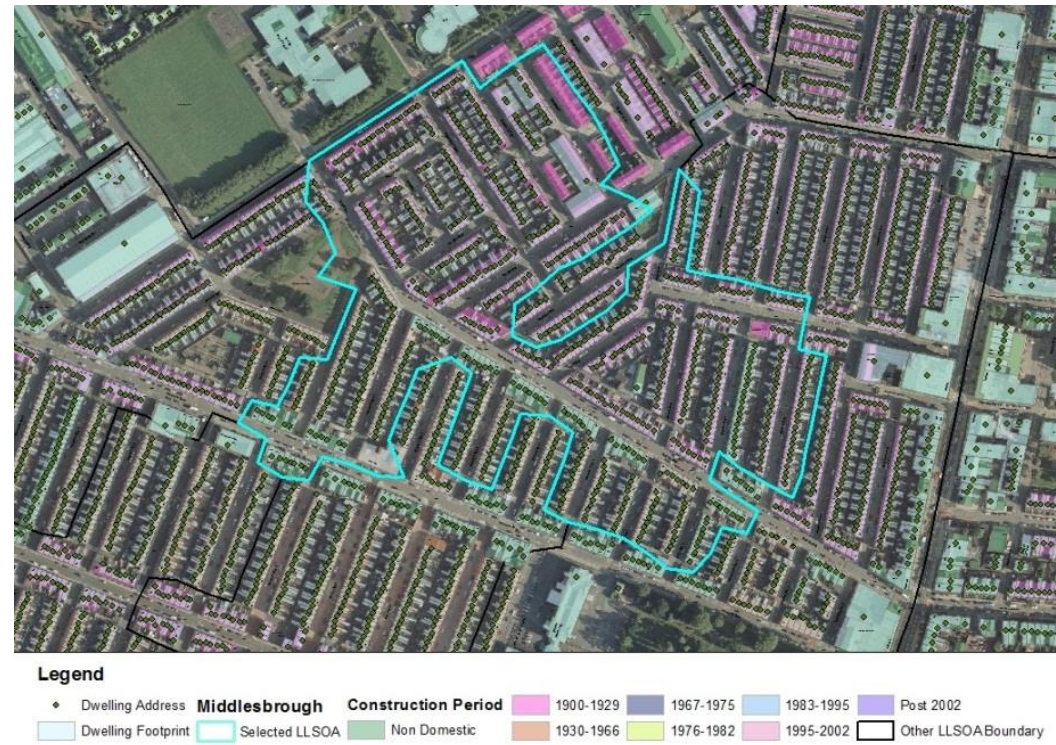

Figure 1: Vector maps and aerial imagery showing LLSOA for case study

The dwellings consisted of a majority of terraced houses followed by a small number of semidetached and detached dwellings of different age groups as shown in Figure 1. The annual energy consumption details for these house types estimated using the approach developed in this research is presented in Table 1.

Table 1: Summary of Energy Consumption in LLSOA

\begin{tabular}{rlrc}
\hline No. & Dwelling Type & Number & $\begin{array}{c}\text { Energy Consumption } \\
(\mathrm{kWh} / \text { Annum })\end{array}$ \\
\hline 1 & Terraced & 719 & $15,948,608$ \\
\hline 2 & Semi-detached & 23 & 357,700 \\
\hline 3 & Detached & 14 & 265,387 \\
\hline & Total & 756 & $16,571,695$ \\
\hline
\end{tabular}

The results show an annual energy consumption of just over $16.5 \mathrm{GWh}$. This computes to an average energy consumption of $21.85 \mathrm{MWh}$ per dwelling per year within the LLSOA. The national average energy consumption estimated for domestic dwellings is $19.8 \mathrm{MWh}$ (OFGEM 2011). The estimated energy performance is approximately $10 \%$ higher than the national average. The results can however be considered 
consistent as most of the dwellings in this LLSOA are pre-world war properties and have low insulation standards (HEED 2012).

The prototype was further used to estimate the energy saving potential of the same dwellings. The average wind speed in this area of Middlesbrough was less than the required $5 \mathrm{~m} / \mathrm{s}$ and hence was not considered suitable. Table 2 shows the results from the analysis of various interventions including changes to building fabric and installation of Solar PV, $\mu$-CHP, condensing boiler and ASHP. Since most dwellings in this area are terraced houses, space is a constraint for ground source heat pumps, hence only air source heat pumps (ASHP) are considered.

Table 2: Quantification of energy saving potential in LLSOA

\begin{tabular}{|c|c|c|c|c|c|}
\hline Intervention & Fixed Cost & $\begin{array}{c}\text { Energy } \\
\text { Saved } \\
\text { (MWh/Year) }\end{array}$ & $\begin{array}{l}\mathrm{CO}_{2} \text { Saved } \\
\text { (Tons/Year) }\end{array}$ & Annual Savings & $\begin{array}{l}\text { Lifetime } \\
\text { Savings }\end{array}$ \\
\hline Fabric Change & $£ 5,973,156$ & 9,084 & 1,795 & $£ 281,090$ & $£ 8,432,708$ \\
\hline Solar PV & $£ 4,309,200$ & 631 & 127 & $£ 217,123$ & $£ 5,428,080$ \\
\hline$\mu$-CHP & $£ 1,814,400$ & 1,311 & 678 & $£ 259,308$ & $£ 5,186,160$ \\
\hline $\begin{array}{l}\text { Condensing } \\
\text { Boiler }\end{array}$ & $£ 1,209,600$ & 585 & 115 & $£ 24,158$ & $£ 483,179$ \\
\hline $\begin{array}{l}\text { ASHP } \\
\text { (underfloor) }\end{array}$ & $£ 6,804,000$ & 4,005 & 793 & $£ 123,984$ & $£ 3,719,520$ \\
\hline $\begin{array}{l}\text { ASHP } \\
\text { (Radiator) }\end{array}$ & $£ 4,536,000$ & $-1,037$ & -205 & $-£ 32,130$ & $-£ 963,900$ \\
\hline
\end{tabular}

The results indicate that for this LLSOA, fabric insulation and use of $\mu$-CHP offer the most $\mathrm{CO}_{2}$ reduction potential for investment made. While the use of ASHP using radiators currently offer no savings in energy used due to their low efficiencies. The ASHP using under-floor heating appear to have good impact on $\mathrm{CO}_{2}$ reduction however is currently cost intensive. Further analyses of the results show that, just by improving the fabric of the building through insulation of solid walls and roof and installation of low emissivity double glazed windows can reduce the energy demand by $9,084 \mathrm{MWh}$ or just over $41.5 \%$. Installation $\mu$-CHP and solar PV can further contribute $15 \%$ of total energy thus reducing the demand from the national grid.

This information was then presented to stakeholders in a focused group to determine the ranking of the improvement measures based on their criteria for selection. The intensity values from pairwise comparison of the criteria and the alternatives were evaluated using AHP described earlier. The results from this process are presented in 
Table 3. The results indicate that improving building fabric is the most popular choice. This is consistent with the current poor quality of the dwelling stock in the area and the amount of energy savings it has to offer. $\mu$-CHP is more popular than the boiler as the former is not only high in efficiency but also generates electricity. ASHP are the least popular most likely reasons being low efficiencies and high installation costs.

Table 3: Rankings for improvement alternatives using decision support

\begin{tabular}{lcccccc}
\hline Alternative & $\begin{array}{c}\mathrm{CO}_{2} \\
\text { Reduced }\end{array}$ & $\begin{array}{c}\text { Initial } \\
\text { Invest. }\end{array}$ & $\begin{array}{c}\text { Return on } \\
\text { Invest. }\end{array}$ & $\begin{array}{c}\text { Social } \\
\text { Accept. }\end{array}$ & $\begin{array}{c}\text { Ease of } \\
\text { Implemen. }\end{array}$ & Goal \\
\hline Fabric & 0.1403 & 0.0550 & 0.0674 & 0.0359 & 0.0219 & $32.05 \%$ \\
Change & & & & & & \\
\hline$\mu$-CHP & 0.1103 & 0.0801 & 0.0517 & 0.0282 & 0.0125 & $28.29 \%$ \\
\hline Solar PV & 0.0663 & 0.0582 & 0.0349 & 0.0170 & 0.0086 & $18.50 \%$ \\
\hline Condensing & 0.0359 & 0.0561 & 0.0136 & 0.0092 & 0.0048 & $11.95 \%$ \\
Boiler & & & & & & \\
\hline ASHP & 0.0218 & 0.0451 & 0.0093 & 0.0056 & 0.0104 & $9.21 \%$ \\
\hline
\end{tabular}

\section{CONCLUSION}

This paper presented a framework that integrates visual systems, databases and decision support system to rapidly evaluate energy performance of the dwellings. The validation using the prototype has showed that the framework provides reliable estimates of energy consumption and enables a systematic analysis of various energy efficiency and renewable energy interventions and eliminating the drive-by surveys. The equations modeled to quantify the energy savings give stakeholders a clear idea on which interventions are more applicable for particular characteristics. For e.g. the tool predicts that for a dwelling having good fabric insulation and hence low heat demand, $\mu$-CHP may not be an ideal choice as low amount of electricity will be generated. The decision support system takes into consideration the opinion of the stakeholders which will help in identifying and eliminating the barriers of implementing energy improvement measures, particularly in the privately owned and privately rented housing sector. The developed framework and the prototype make an attempt to address the requirement of a tool for stakeholders to make informed decisions regarding implementation of energy policy.

\section{REFERENCES}

Boardman, B. (2007). Home Truths: A low carbon strategy to reduce UK housing 
emissions by $80 \%$ by 2050. University of Oxford's Environmental Change Institute.

DECC/BRE. (2010). The Government's Standard Assessment Procedure for Energy Rating of Dwellings. Building Research Establishment. Watford, UK.

Environmental Systems Research Institute. (2010). A quick tour of what's new in $\operatorname{Arc} G I S 10$.

Firth, S., K., Lomas, K., J., Wright, A.,J. (2010). Targeting household energy-efficiency measures using sensitivity analysis. Building Research and Information, Vol. 38 No. 1, 24-41.

HEED. (2012). Area Summary Report (Middlesbrough, Middlesbrough South and East Cleveland). Energy Savings Trust.

Jenkins, D., P. (2010). The value of retrofitting carbon-saving measures into fuel poor social housing. Energy Policy, Vol. 38, 832-839.

Johnston, D. (2003). A physically based energy and carbon dioxide energy model of the UK housing stock. PhD Thesis, Leeds Metropolitan University.

Jones, P., Patterson, J., Lannon, S. (2007). Modelling the built environment at an urban scale - energy and health impacts in relation to housing. Landscape and Urban Planning, Vol. 83, 39-49.

Mhalas, A., Kassem, M., Crosbie, T. and Dawood, N. (2013). A visual energy performance assessment and decision support tool for dwellings, Visualization in Engineering 2013, 1:7.

OFGEM (2011). Typical domestic energy consumption figures. Office of Gas and Electricity Markets. London, UK.

Peacock, A., D., Turan, S., Jenkins, D., Ahadzi, M., Bowles, G., Kane, D., Newborough, M., Eames, P., C., Singh, H., Jackson, T., Berry, A. (2007). Reducing $\mathrm{CO}_{2}$ emissions through refurbishment of UK housing. European Council for an Energy Efficient Economy.

Pohekar, S., D. \& Ramachandran, M. (2004). Application of multi-criteria decision making to sustainable energy planning - A review. Renewable \& Sustainable Energy Reviews, Vol. 8, 365-381.

Saaty, T., L. (1980). The analytic hierarchy process. Macgraw-Hill.

Shorrock, L. D., \& Dunster, J. E. (1997). The physically-based model BREHOMES and its use in deriving scenarios for the energy use and carbon dioxide emissions of the UK housing stock. Energy Policy, Vol 25 No. 12, 1027-1037.

Wang, J., J., Jing, Y., Y., Zhang C., F., Zhao, J., F. (2009). Review on multi-criteria decision analysis aid in sustainable energy decision-making. Renewable and Sustainable Energy Reviews, Vol. 13, 2263-2278. 